\title{
Information Technology and Its Effects on Urban Communities: With Special Reference to Bangalore City
}

\author{
Vinodh Kumar G.C. \\ Junior Research Fellow, Department of Sociology, Bangalore University, Bangalore-560056.
}

\begin{abstract}
Information technology is playing a vital role recent past. It is one of the fastest growing industries. As an era, IT has revolutionized many aspects of our society and hence it is being debated widely in government, corporate, academic and civil society. The ever and fast growing IT and related industry along with the service industry have impacted various aspects of our social life. As a result, the fast growing information technology industries have produced an impact on society, in the grounds of social, economic, cultural and moral aspects. The impact is being discussed in terms of changes in the institutional and practice lines of the people resulting in the emergence of new cultures and practices. In contemporary society there are huge discussions on information technology and its effects on the society. It has significant impact on the traditional culture and a drastic change is been seen in the culture of urban communities. The ethics and morals are been changing which is been directly or indirectly impacting on the younger generations of the society. The traditional structure of the urban cities is been in great danger which shows the negative growth of the individual's in the society. The objective of the study is to know about the socio-cultural changes taking places and the effects on socio, economic, cultural and moral aspects. This paper aims at identifying variables' which result in such change. Though there are innumerable variables which alter every day with varying degrees, the necessity to identify and possible control of these variables are being explored in this study.
\end{abstract}

Keywords: Community, Culture, Economic, Social, Tradition

\section{Introduction}

The first phase of revolution took place in the name of Agriculture by the invention of wheel in the ancient society. The second phase Industrial revolution came into existence due to invention of machinery which has created an enormous knowledge towards the use of machinery in production of goods and services to the society.Later in the present and third phase of revolution led to the rise of service sector where Information Communication Technology and ITES came into existence. But it has impacted both positively and negatively on the social, economic, political and cultural lifestyles of the human beings. India has also experienced the changes due to the influence of industrialization and changes in the urban communities because majority of the industries are located in and around urban locality.

India is a country comprising of multi-cultural, multi-linguistic and multi-traditional aspects. But from past two decades urban communities in India is experiencing the rapid change in its culture, tradition, ethics and moral aspects due to the fast growth of IT industries and it is effected by both positive and negative aspects. Indian IT companies have various streams such as IT Services, ITES-BPO, Engineering services, R\&D and Software products and Hardware. Majority IT related industries are established only in and around urban centers in India, especially Bangalore, Hyderabad, Chennai, Noida, etc. But among them Bangalore has acquired a prominent position in IT industry where all parts of the country people are employed.

TABLE 1.1: IT SECTORS RANKING

$\begin{array}{cc}\text { RANKING } & \text { CITY } \\ 1 & \text { BANGALORE } \\ 2 & \text { CHENNAI } \\ 3 & \text { HYDERABAD } \\ 4 & \text { PUNE } \\ 5 & \text { NCR }\end{array}$

Source: Wikipedia 
TABLE 1.2: WORKFORCE OF INFORMATION TECHNOLOGY INDUSTRY IN INDIA

\begin{tabular}{rlrr}
\hline SL & NAME OF & THE & $\begin{array}{l}\text { MAJOR } \\
\text { WORKFORCE }\end{array}$ \\
\hline 1 & CITY & COMPANIES \\
2 & DELHI \& NCR & $1,09,500$ \\
3 & MUMBAI & 73,000 \\
4 & CHENNAI & 62,050 \\
5 & HYDERABAD & 51,100 \\
Source: Wikipedia & 36,500 \\
\end{tabular}

Bangalore is popularly known as the capital of the Silicon Valley of India and is currently leading in Information Technology Industries in India. Chennai is the Second largest exporter of Software next to Bangalore. It has the largest operations for India's top software company TCS, Infosys and other software companies like Wipro, CTS, Patni, L\&T InfoTech and many companies have major operations in IT corridor, Ambattur and other places in Chennai. Hyderabad, called Cyberabad, which has good infrastructure and good government support is also a good technology base in India. The Government of AP has built a separate township for IT Industry called the HITEC City. Pune is a major industrial point in India. The National Capital Region of India comprising Delhi, Noida, Greater Noida, Ghaziabad, Gurgaon, Faridabad and are having ambitious projects and are trying to do every possible thing for this purpose. But due to the higher job opportunities in Bangalore city has led to the pull factor all over the country. The employees working in IT sector are from various parts of the country which have led to the rise of mixed culture especially in Bangalore. Moreover the western influences have resulted in negative growth which has effects on the local urban communities.

\subsection{CONCEPTUALIZATION:}

Information technology is a broad subject concerned with technology and other aspects of managing and processing information, especially in large organization. In particular, IT deals with the use of electronic computers and computer software to convert, store, protect, process, transmit, and retrieval information. For that reason, computer professionals are often called IT specialists, ITians and the division of a company or university that deals with software technology is often called the IT department. IT includes hardware, database, software, and other resources suitable for information processing. Since the 1990s, information technology (IT) has emerged as an essential element in the business environment.

A community is a self-conscious social unit and a focus of group identification. Gemeinschaft and Gesellschaft speak about community and society (Tonnies, 1887), He is also known as the Father of theory of community. Community is the term we apply to a pioneer settlement, a village, a city, a tribe, or a nation. Whenever the members of any group, small or large, live together in such a way that they share, not this or that particular interest, but the basic conditions of a common life, we call that group a community (Maciver, 1937). Boothroyd (1990) a community is 'A Human system of more than two people in which the members interact personally over time, in which behavior and activity are guided by collectively- evolved norms or collective decisions, and from which members may freely secede'.Bill Lee (1992) defines community, simply as a group of people who have something in common. In Greek language it means "fellowship" or a group of people who come together for mutual support and to fulfill their basic needs.

\section{Review of Literature}

The impact of science and technology should implement a positive policies regarding social development for the better of the society from the concern towards political and social concern and more over women employees should be provided proper security, by Gloria Bonder. Stewart Witing Chong has expressed about the sustainable development in developing countries through IT industry and has ousted the impact of ICT and to create the global knowledge networks and to improve the poor communities. MehriEzadiYoganesh has spoken about the National culture and organizational culture on the development and use of information and communication technologies. He also has made an attempts define the National culture and organizational culture. Greg Laudeman has said about the information technology and community-level socio-economic development and pointed out the gaps and difficulties in the process. Nancy Chase has studies about the culture of information Technology and focus on unrelenting change where she has used three stages, the constrictive aspects of changes, difficult aspect of change and change and IT culture by using various sociological theories.

Panini (1988) has discussed about corporate culture in India. The study of Indian corporate culture not only contribute to effecting changes in corporate culture but will also help in altering the direction of social change in India. Under the impact of modern technology, changes are occurring in the composition of manager cader. Barbara, Shirley, Valerie(2003) have discussed about the technology implementation to the school 
teaching but they have found a community development in the learners which made learners to be more open in sharing their thoughts and experiences. Cohendet, Creplet, Diani, Dupouet and Schenk (2004) have made a study about 'knowledge-intensive communities'. The governance of the firms as a community of communities aims at benefiting from the diversity of interactions between communities. It seeks to bridge the hierarchical architecture of learning, which is based on communities.Swarup (2005) has discussed the future development in the international markets and practices. He has pointed out that some companies like, TISCO, Wipro, HLL have their own strategic planning. Murdoch (2005) has discussed integration and disintegration of community development, comprehensive redevelopment to community planning, local community planning and structuring community involvement.

Anita (2006) has discussed information and communication technologies have created new economic and social opportunities to the women and promoting gender equality through global women's movement.Cooper (2008) has discussed the policy literature of community development. The conflict should be regarded as a positive dynamic which is essential to healthy democratic life. Jha (2009) has discussed about the challenges for community organization practices in enhancing of plural living and tolerance in a democratic society. Andharia (2009) has discussed about the critics of community organization in India and impact of community organization in poverty, food insecurity and inequality; education and health and water. Likewise there are several studies which have been focused on community development.Pandey (2010) has discussed communitization is a contract between the government and the community, in this contract the community becomes the owner of the government institutions and assets and is granted powers and resources to manage the employees and maintain institutions. He enlightens the potential benefits of social capital in today's world.

Traditionally, sociologists have referred to the study of how groups of people share meaning and resolve their common problems as the study of culture (e.g., Barley, 1983; Hofstede, 1991; Louis, 1980; Schein, 1992). Later research describes contemporary organizations as multicultural entities (e.g., Barley, 1996; Gregory, 1983; Martin, 1992; Schein, 1996). The occupational culture perspective focuses on the meaning of the work role from the perspective of those who engage in it (Chase, 2002). "Members of occupational communities are favorably oriented toward their jobs and careers. To them, work is more than merely 'making a living;' it is a source of meaning and value" (Van Maanen\& Barley, 1984, p. 308). Several studies have identified elements of an occupational culture in technical employees of various kinds. The research of Gregory (1983) examined the "native" viewpoint of Silicon Valley technical professionals and focuses on how technical professionals from a wide variety of companies managed their careers. Kaarst-Brown and Robey (1999) presented a cultural theory relative to the management of IT utilizing the metaphor of myth and magic to describe archetypes of IT culture.Prager (1999) maintained, "We all know intuitively that IT professionals behave differently than everyone else. . . . In fact, separate organizational cultures exist for IT professionals and non-IT employees based on a different set of organizational behaviors". Interestingly, Prager also reported that the world view of IT professionals has a tendency to change over time, and eventually these professionals may behave more like non-IT employees. This finding parallels the study of Sornes, Stephens, Saetre, and Browning (2004) which discovered few differences between the use of information and communication technologies by knowledge workers of Norway and the United States. Travica (2008) investigated the concept of information culture as a component of organizational culture and explored its influence on the implementation of self-service software. "Within the discipline of information systems, the concept of culture is generally regarded as being very important" (Avison\& Myers, 1995).

But present day ITians culture is been playing an important role in the Indian society, even though they represent very less work force. In Bangalore ITians culture is greatly impacting on urban communities in the form of social, cultural, personal and moral aspects.

The main objectives of the study are as follows: -

\section{Objectives of the Study}

- To analyze the impact of Information Technology on urban communities.

- To analyze the socio-culturaland economic aspects.

\section{IV.Rational Of the Study}

The emergence of liberalization, privatization and globalization has led to the vast development of information technology industry in India. The urban local communities in India have been growing in the negative aspect. In the state of Karnataka new type of developments are raising day by day from the impact of IT. Bangalore as the capital of IT industry the socio, economic, cultural and traditional aspects are affected by IT firms. In this regard there is a need to study the emerging problems related to urban community. 


\section{Methodology Of The Study}

This paper aims at identifying 'variables' which result in such change. Though there are innumerable variables which alter every day with varying degrees, the necessity to identify and possible control of these variables are being explored in this study. At present, the paper is purely based on secondary sources such as articles, journals, books, newspapers and internet websites.

\section{Results And Discussion}

Few of the variables are identified and discussed to analyze the problems which are affected to the urban communities due to the impact of Information Technology.

6.1 Social aspect: -

In present day scenario the rate of divorce is raising day by day in Bangalore. According to the data available from the family court Bangalore, Out of $100 \%$ divorce cases $70 \%$ of the divorce cases are registered by IT employees. While comparing the data in the year 2005 the divorce rate among IT professionals was $30 \%$ and have reached to $70 \%$ in the year 2010 , a rapid growth can be seen which is negatively effecting the urban communities and surrounding culture. While in the case at marriage the number of marriages has increased that to Gandharva Marriage in present day it is been named as love marriage. According to the data available from various sources it is been identifies that $40 \%$ of the IT professionals get love marriage. By this activity the negative effect on the customs, traditions and moral values are been lost in and around Bangalore city which has created a major effect of urban communities.In the case of domestic violence, the available data speak that the rate of domestic violence in high among IT professionals but the registered cases show the low rate, due to the high no of divorce cases. The Information Technology boom in Bangalore is not unknown. But the major problem arising is divorce. A majority of those filing for divorce are young, typically in their late 20s and early $30 \mathrm{~s}$, and work in the city's burgeoning corporate sector. Statistics reveal that in 2006 alone, 1,246 cases of divorce pertaining to those in the IT sector have landed in the matrimonial courts in Bangalore. Financial freedom, lack of time at home, erratic working hours, work pressure, financial security and stress are being seen as the main reasons for this fiasco. The worrying factor is that the number of divorce cases pertaining to those in the IT sector has seen a steady rise since 2003. In 2003, the number of cases from the IT sector was 283 while in 2004 it went up to 526. Statistics available show that in 2005, the figure went up to 946 and in 2006 the figure was 1,246 . India's IT City is also the divorce capital of South India. There are at least 25 divorce cases filed every day. Between January and June 2010, 1,400 couples decided to part ways. The cases coming to the family court, at least $80 \%$ are filed under the Hindu Marriage Act. While $70 \%$ of couples are from the IT sector, BPOs and private companies, $30 \%$ are from the other sections of society, said a source in the family court. Thirty per cent of the cases are from the lower middle-class filed under Domestic Violence Act. Financial stability is a major cause for the rise in divorces. Couples do not try to save the marriage as they are confident they can lead an independent life as both of them are financially stable.InBangaloreITians are known to solve the toughest problems in the computer world using complex algorithms, but when it comes to marriage the smallest problem takes a toll on them. The pressures of the modern workplace have made a bigger difference in the lifestyle of ITians.According to lawyers in the city, 30 percent of all divorces that happen in the city every year are among couples working in the IT sector, and 50 percent of them use hacking techniques to collect electronic evidence against each other. In many cases people meet on social networking sites and choose to marry without checking each other's background.

\subsection{Economic aspect: -}

While seeing the economic perspective the economic development / growth are high in Bangalore rather than IT hub cities in India. The GDP ratio and the NI rate are increasing day by day. But due to the economic stability of the ITians in the Bangalore city has created a new class inside the class system. It has resulted in the expansion of middle class strata in Bangalore. The lifestyles, food habits and western outlook have raised due to the impact ITians economic stability and new firms like hotels, restaurants and many other business firms are rising in the name of service sector. These are all the impact of globalization and $2^{\text {nd }}$ industrial revolution. By all this issues the urban communities are affected by one or the other reason.

\subsection{Cultural aspect:-}

The information regarding cultural change due to the impact of ITians is been collected from various sources change is inevitable but the change taking place should be health and should lead to the positive growth of the society for better future next generations. Pre-martial affairs have been increased in Bangalore and are high among ITians which is breaking the morals of the Bangalore urban communities. Extra martial affairs are also have increased over a period of time and no of cases are registered due to the extra martial affairs among ITians which has direct negative effects on the younger generation and also on the morals of the society.Migration from other states to Bangalore has raised over a period of time due to the high employment 
opportunities in IT firm in Bangalore which has resulted in rising five in relationship which in against the custom, morals and traditions of urban communities and it has also an impact on youth and younger generation.

\subsection{Educational aspect: -}

Education qualification is very important in our society and for developing country like India it is a capital for development. The impact of globalization has given a way for new forms of education and specialization in many aspects. Today the pattern of education is been changing. Young generation people are moving towards diploma courses and some job oriented courses rather than moving towards higher education. In Bangalore some educational institutions has opened many private courses where large number of youth are attracted towards it and young generation prefer to join IT industry rather than other firms. This type of development has proceeded to downfall higher education especially in Bangalore. Moreover urban community younger generation has started following the IT related courses, which result in negative growth of knowledge capital. This may lead to the downfall of basic educational system and we may forget about some social science and science subjects in future and it may be a great loss for our upcoming generations.

\section{Findings Of The Study}

1. This study has found that the divorce has become a rising social evil in Bangalore among ITians.

2. The ITians culture has directly or indirectly effecting on urban communities.

3. Economic stability has provided them a lot of opportunity for committing mistakes.

4. The moral aspects of the society is been damaged in high rate due to the impact of ITians.

5. A shift towards new form of education.

\section{VIII.Suggestions Of The Study}

1. Urban policies should be changed and make new policies to save the moral and ethics of the urban communities.

2. Bangalore city culture is been effected due to the impact of ITians should be noticed by other IT hub cities and should take preventive measures to avoid the problems.

3. Should undertake awareness program for the ITians in IT firms regarding the increased ratio of social, economic and cultural impact and to make them to save the moral and ethics of the society.

4. To take necessary steps towards education system, like introducing new papers, new subjects along with existing subject and motivate students to proceed towards higher education.

\section{Conclusion}

Change is inevitable; however, the attempt to change the course of change should be in the hands of the rational, intelligent citizens of the society so that the environment, society, culture, and human race are not affected significantly.

\section{Acknowledgement}

I am thankful to DR. R. Rajesh, Associate Professor, Department of Sociology, Bangalore University, Bangalore, for his suggestions and continuous support.

\section{References}

[1] Andhari, Janki, (2009), "Critical Explorations of Community Organizations in India", Community Development Journal, 44, 3, pp. 276-290.

[2] Dale W. Jorgenson and Kevin J. Stiroh, (1999), “Information Technology and Growth", The American Economic Review, Vol. 89, No. 2, pp 109-115.

[3] Francois-Xaveir de Vaujany, (2005), "Information Technology Conceptualization: Respective Contributions of Sociology and Information Systems", Journal of Sociology and Information Systems, Vol.5, No. 1, pp 39-58.

[4] Guha, Abijit. (2011) 'Challenges to Corporate Social Responsibility: A Case Study from Kharagpur, West Bengal', Sociological Bulletien, 60:1

[5] Jha, Manoj, (2009), "Community Organization in Split Societies”, Community development Journal, 44, 3, pp. 305-319.

[6] Kalpana G, (2010), "Torn in Two: The Tale of Two Bangalores Competing Discourses of Globalization and Localization in India's Information City", Dharana- Bhavan's International Journal of Business, Vol. 4 No. 2, pp. 83-92.

[7] Marvin D. Krohn, LonnLanza-Kaduce, Ronald L. Akers (1984), "Community Context and Theories of Deviant Behavior: An Examination of Social Learning and Social Bonding Theories" The Sociological Quarterly, Vol. 25, No. 3 pp. 353-372

[8] Panini, M.N., (1988), "Corporate Culture in India", Economic and Political Weekly, 23, 35, pp. 86-94.

[9] Paul Tracey, Nelson Phillips, Helen Haugh (2005), "Community Enterprise as a Basis for Corporate Citizenship", Journal of Business Ethics, Vol. 58, No. 4 pp. 327-344.

[10] Swarup, K.Mohanly (2005), "Corporate, social Responsibility: Present practices and Future Possibilities", Indian Journal of Industrial Relations, 40.1, pp-547-557.

[11] AmitaiEtzioni\& Richard Remp (1973), "Technological Shortcuts to Social Change”, Russell sage foundation, New York.

[12] Bertrand Russell (1958), "The Impact of Science on Society", Blackie \& son ltd.., Bombay.

[13] Bhalla A. S. (1996), "Facing the Technological Challenge", Macmillian press ltd. 
[14] Daniel Bell, (1974), "The Coming of Post-Industrial Society”, Arnold- Heinemann Publishers, New Delhi.

[15] Daniel lee Kleinman (2005), "Science and Technology in Society", Blackwell publishing.

[16] Jayaram N (2004), "The Indian Diaspora”, Sage publication, New Delhi.

[17] Kennithkeniston, Deepak Kumar (2004), "IT Experiences in India", sage publication.

[18] Louis Dumont (2002), "Homo Hierarchicus", Oxford University Press.

[19] M.C.Sharma, (1981), "The Knowledge Class", Marwah Publication.

[20] Mark J. smith (2002), "Culture-Reinventing The Social Sciences", Viva books Pvt.

[21] Mills C.W., (1959) “The Sociology Imagination”, Oxford University Press, New York.

[22] Natasha Primio (2003), "Gender Issues in the Information Society", UNESCO Publication, Paris.

[23] Nirmalkumarbose (1901), "Culture and Society in India", Asia publishing house.

[24] Ram A (2002), "Indian Social System", Rawat Publication, Jaipur.

[25] Raymond plant (1974), "Community and Idealogy", Routledge and keganpaul Publication, London \& Boston.

[26] Salaman, Graeme (1981), 'Class and the Corporation', Fontana paperback.

[27] Somashekharapa C.A. and Gurumurthy K.G., (1993), "Community Studies and Community Development", Reliance Publication House, New Delhi.

[28] Castells, Manuel, (1999), “Information Technology, Globalization and Social Development", UNRISD Discussion paper No. 114. Geneva, Switzerland.

[1] http://ncrb.nic.in/ciiprevious/main.htm

\section{Webliography}

[2] http://news.oneindia.in/2011/10/28/bangalore-loses-it-tag-now-suicide-capital-of-india.htm

[3] http://newshopper.sulekha.com/in-bangalore-rising-divorce-rate-in-it-sector_news_842600.htm

[4] http://www.call-centers-india.com/major-call-center-cities-india.html

[5] http://www.clickindia.com/detail.php?id=10845064

[6] http://www.dnaindia.com/bangalore/report_another-tag-for-bangalore-divorce-capital_1575841

[7] http://www.globalenvision.org/library/8/1224

[8] http://www.window2india.com/ cms/admin/article.jsp?aid=2165 